\author{
Физико-химические и биологические свойства биоподобного \\ и референтного препаратов тканевого активатора плазминогена \\ В. Д. Гусарова, М. С. Пантюшенко, В. М. Симонов, Р. Р. Шукуров, Р. А. Хамитов, А. Ю. Вишневский* \\ Общество с ограниченной ответственностью \\ «Международный биотехнологический центр «ГЕНЕРИУМ», \\ ул. Владимирская 14, пос. Вольгинский, Петушинский район, \\ Владимирская область, 601125, Российская Федерация
}

\begin{abstract}
Рекомбинантный тканевой активатор плазминогена (международное непатентованное название - алтеплаза), разработанный и зарегистрированный компанией АО «ГЕНЕРИУМ» (Россия), является полным аналогом лекарственного препарата Актилизе ${ }^{\circledR}$, используемого для лечения заболеваний, сопровождающихся тромбообразованием, таких как инфаркт миокарда, тромбоэмболия легочной артерии и ишемический инсульт. Цель работы: провести комплексное исследование сопоставимости фризико-химических и биологических характеристик лекарственного препарата Ревелиза ${ }^{\circledR}$ и рефрерентного препарата Актилизе ${ }^{\circledR}$ для оценки их биоподобия. Материалы и методы: сравнительное пептидное картирование с определением сопоставимости хроматографических профилей триптических гидролизатов проводилось методами ОФ-ВЭЖХ и масс-спектрометрии, определение молекулярно-массового распределения - методами масс-спектрометрии и электрофореза в полиакриламидном геле по Леммли. Для определения чистоты и гомогенности препаратов, а также содержания родственных примесей (олигомеров, фрагментов) использовали метод гель-фильтрации; исследование профиля N-гликозилирования осуществляли методом гидрофильной ВЭЖХ, определение тотального содержания сиаловых кислот - методом Свеннерхольма. Оценку связывания белка с фибрином и фибриногеном человека проводили методом поверхностного плазмонного резонанса, сравнение специфической активности - методом лизиса фибринового сгустка. Результаты: в ходе исследований было продемонстрировано полное совпадение пептидных карт анализируемых препаратов, что свидетельствует об идентичности аминокислотной последовательности алтеплазы в составе сравниваемых препаратов. Также сравнительно были определены молекулярная масса и содержание интактной одноцепочечной фрормы белка в лекарственных препаратах, количественно охарактеризованы посттрансляционные модификации, содержание сиаловых кислот и нейтральных сахаров. При изучении профиля $\mathrm{N}$-гликозилирования обнаружены незначительные различия в процентном содержании мультиантенных комплексных гликанов. Специфичность алтеплазы оценивали при образовании белковых комплексов с природными лигандами алтеплазы - фрибрином и ингибитором активатора плазминогена первого типа, при этом достоверных различий обнаружено не было. При сравнении специфической активации фибринолитической активности плазминогена в тесте на скорость лизиса фибринового сгустка была продемонстрирована сопоставимость препаратов Ревелиза ${ }^{\circledR}$ и Актилизе ${ }^{\circledR}$. Выводы: проведенные сравнительные экспериментальные исследования показали отсутствие различий в структуре, гетерогенности распределения зарядов, содержании примесей, а также специфической активности алтеплазы в составе лекарственного препарата Ревелиза ${ }^{\circledR}$ и референтного препарата Актилизе ${ }^{\circledR}$, что позволяет сделать вывод о сопоставимости препаратов по фризико-химическим и биологическим свойствам.

Ключевые слова: тканевый активатор плазминогена; биоаналог; Актилизе ${ }^{\circledR}$; Ревелиза ${ }^{\circledR}$; профриль гликозилирования; посттрансляционные модификации; лизис фибринового сгустка
\end{abstract}

Для цитирования: Гусарова ВД, Пантюшенко МС, Симонов ВМ, Шукуров РР, Хамитов РА, Вишневский АЮ. Физико-химические и биологические свойства биоподобного и референтного препаратов тканевого активатора плазминогена. БИОпрепараты. Профилактика, диагностика, лечение. 2019;19(1):3949. https://doi.org/10.30895/2221-996X-2019-19-1-39-49

“Контактное лицо: Вишневский Александр Юрьевич; vishnevskiy@ibcgenerium.ru

\title{
Physico-Chemical and Biological Properties of Biosimilar and Reference Tissue Plasminogen Activator Products
}

\author{
V. D. Gusarova, M. S. Pantyushenko, V. M. Simonov, R. R. Shukurov, R. A. Khamitov, A. Yu. Vishnevskiy* \\ International Biotechnology Center «GENERIUM», \\ 14 Vladimirskaya St., Volginsky town, Petushinsky District, \\ Vladimir Oblast 601125, Russian Federation
}

\begin{abstract}
Recombinant tissue plasminogen activator (international nonproprietary name - alteplase) which was developed by "GENERIUM» (Russia) and received a marketing authorisation in Russia is completely analogous to Actilyse ${ }^{\circledR}$ which is used to treat medical conditions accompanied by thrombosis, such as acute myocardial infarction, pulmonary embolism, and ischemic stroke. The aim of the study was to carry out a comprehensive comparison of physico-chemical and biological properties of Revelyse ${ }^{\circledR}$ and the reference product Actilyse ${ }^{\circledR}$ in order to assess their biosimilarity. Materials and Methods: comparative peptide mapping and determination
\end{abstract}


of comparability of chromatographic profiles of tryptic hydrolysates was performed using RP-HPLC and massspectrometry; the molecular weight distribution was determined by mass-spectrometry and polyacrylamide gel electrophoresis (Laemmli method). The purity and homogeneity of products as well as the content of related impurities (oligomers and fragments) were determined using gel filtration; N-glycosylation profile was analysed by hydrophilic HPLC, total sialic acid was quantified by the Svennerholm resorcinol method. Protein binding to fibrin and human fibrinogen was assessed by surface plasmon resonance, and the specific activity was compared by fibrin clot lysis. Results: the research demonstrated a complete overlap of the products' peptide maps, which indicates the identity of alteplase amino acid sequences in the two medicines being compared. The authors of the study also determined the molecular weight and the content of the intact single-stranded form of the protein, and quantified post-translational modifications, the content of sialic acids and neutral sugars. The analysis of the $\mathrm{N}$-glycosylation profile revealed insignificant differences in the percentage of multiantenna complex glycans. The specificity of alteplase was evaluated by analysing the formation of protein complexes with natural alteplase ligands - fibrin and plasminogen activator inhibitor-1, but no significant differences were found. The comparison of specific activation of plasminogen fibrinolytic activity was performed based on the results of the assay analysing the fibrin clot lysis rate, and it demonstrated comparability of Revelyse ${ }^{\circledR}$ and Actilyse $^{\circledR}$. Conclusions: comparative experimental studies have shown no differences in the structure, charge distribution heterogeneity, impurities content, and specific activity of alteplase as a component of Revelyse ${ }^{\circledR}$ and the reference product Actilyse ${ }^{\circledR}$, which leads to the conclusion that they are similar in terms of physicochemical and biological properties.

Key words: tissue plasminogen activator; biosimilar; Actilyse ${ }^{\circledast}$; Revelyse $^{\circledR}$; glycosylation profile; post-translational modifications; fibrin clot lysis

For citation: Gusarova VD, Pantyushenko MS, Simonov VM, Shukurov RR, Khamitov RA, Vishnevskiy AYu. Physico-chemical and biological properties of biosimilar and reference tissue plasminogen activator products. BIOpreparaty. Profilaktika, diagnostika, lechenie $=$ BIOpreparations. Prevention, Diagnosis, Treatment. 2019;19(1):39-49. https://doi.org/10.30895/2221-996X-2019-19-1-39-49

"Corresponding author: Aleksandr Yu. Vishnevskiy; vishnevskiy @ibcgenerium.ru

Тканевой активатор плазминогена (tPA) является мультидоменной сериновой протеиназой, катализирующей реакцию превращения плазминогена (Pgn) в плазмин (PIm) расщеплением $\mathrm{R}_{561}-\mathrm{V}_{562}$. $\mathrm{PA}$ представляет собой гликопептид, состоящий из 527 аминокислот, которые фрормируют пять пространственных доменов четырех типов: (1) А-домен фрибринонектинового типа I фингер-домен — последовательность 1-43; (2) GF-подобный домен - последовательность 44-91; (3-4) два крингл-домена (kringle I - последовательность 92-173, kringle II - последовательность 180-261), соответствующие kringle-доменам плазминогена и протромбина; (5) протеазный С-концевой фррагмент (последовательность 276-527), гомологичный трипсиновым сериновым протеазам, содержит активный каталитический сайт, состоящий из His322, Asp371 и Ser478 (рис. 1). Присутствующие 35 остатков цистеина образуют 17 внутримолекулярных дисульфидных связей.

Основная роль ТРA, экспрессируемого клетками эндотелия сосудов, заключается в разрушении фрибриновых полимеров посредством активации плазмина, поэтому рекомбинантный человеческий ТРА используется для лечения заболеваний, связанных с тромбообразованием (таких, как инфаркт миокарда, ишемический инсульт и эмболия легочной артерии).

В 1987 году FDA одобрило регистрацию ЛП Актилизе ${ }^{\circledR}$ («Берингер Ингельхайм Интернешнл ГмбХ», Германия) - рекомбинантного человеческого ТPA (МНH Алтеплаза), отличающегося от ранее созданных препаратов преимущественным фрибринолитическим действием и очень слабым влиянием на фибриноген плазмы.

Компанией АО «ГЕНЕРИУМ» (Россия) разработан и зарегистрирован рекомбинантный человеческий тканевой активатор плазминогена (в лекарственной форме лиофилизат для приготовления раствора для инфузий, 50 мг) под торговым названием Ревелиза ${ }^{\circledR}$, являющийся полным аналогом по составу, дозировке и лекарственной форме ЛП Актилизе ${ }^{\circledR}$.
Для регистрации биоподобных лекарственных средств необходимо после оценки качества и доказательства его соответствия установленным требованиям показать схожесть параметров качества, эфффективности и безопасности с референтным биологическим ЛП (в такой же лекарственной фрорме и при идентичном способе введения). Принципы сравнительной оценки биоподобных препаратов подробно изложены в отечественных 1 и международных ${ }^{2}$ нормативных документах. Выбранные методы анализа должны максимально выявить возможные различия в сравниваемых препаратах, способные повлиять на эффрективность и безопасность.

Цель работы - провести комплексное исследование сопоставимости физико-химических и биологических характеристик лекарственного препарата Ревелиза ${ }^{\circledR}$ и ресеерентного препарата Актилизе ${ }^{\circledR}$ для оценки их биоподобия.

\section{Материалы и методы}

\section{Материалы}

Все исследования проводили, используя три серии ресерентного ЛП Актилизе ${ }^{\circledR}$ (серия 606428, дата выпуска: 09.2016, годен до: 09.2019; серия 604030, дата выпуска: 09.2016, годен до: 09.2019; серия 606119, дата выпуска: 09.2016, годен до: 09.2019) и три серии биоподобного ЛП Ревелиза ${ }^{\circledR}$ (серия 011115, дата выпуска: 11.2015, годен до: 12.2017; серия 010116, дата выпуска: 01.2016, годен до: 02.2018; серия 020516, дата выпуска: 05.2016, годен до: 06.2018).

\section{Методы}

\section{1. Пептидное картирование ОФ-ВЭЖХ}

Хроматографические процедуры проводили, используя хроматографическую систему высокого давления Waters 2695 (США).

Пробоподготовку образцов алтеплазы для пептидного картирования проводили согласно методике, описанной

\footnotetext{
1 Руководство по экспертизе лекарственных средств. Том IV; М.: Полиграф-Плюс; 2014.

2 The European Medicines Agency. Similar biological medicinal products containing biotechnology-derived proteins as active substance: quality issues (EMEA/CHMP/BMWP/49348/2005).

The European Medicines Agency. Guideline on similar biological medicinal products containing monoclonal antibodies — non-clinical and clinical issues (EMA/CHMP/BMWP/403543/2010).
} 


\section{Микрогетерогенность tPA (алтеплаза)}

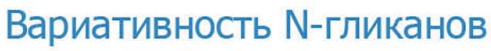

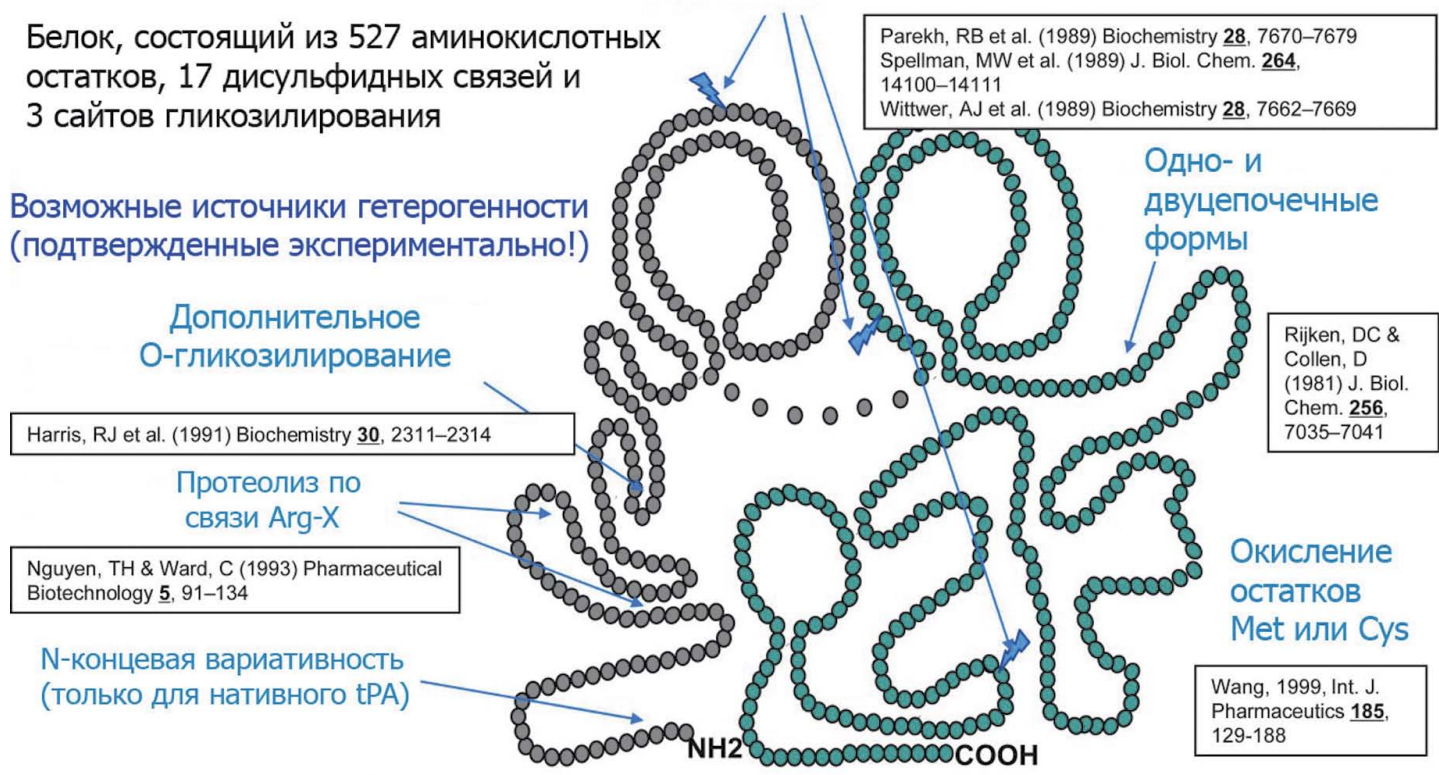

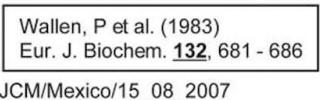

Деамидирование остатков Asn

Zhang, W \& Czupryn, MJ (2003) J. Pharmaceutical and Biomedical Analysis $\underline{\mathbf{3 0}}, 1479$ - 1490

Рис. 1. Пространственная структура алтеплазы с указанием сайтов гетерогенности.

Fig 1. Spatial structure of alteplase with indication of heterogeneity sites.

в EP 9.03. Разделение триптических гидролизатов осуществляли на колонке YMC-Pack ODS-AQ, 100×4,6 мм, 5 мкM, $200 \AA$ (ҮMC, Япония) с использованием подвижных фаз следующего состава - A: 66,6 мM NaH ${ }_{2} \mathrm{PO}_{4} \times \mathrm{H}_{2} 0$, $\mathrm{pH} 2,85 ; \mathrm{B}: 16,6 \mathrm{mM}$ $\mathrm{NaH}_{2} \mathrm{PO}_{4} \times \mathrm{H}_{2} \mathrm{O}, 75 \%$ ацетонитрил, $\mathrm{pH} 2,85$. Скорость потока составляла 1 мл/мин, градиент 5-40 \% В за 90 мин, 40-80 \% В за 30 мин. Детекцию осуществляли при 210 нм.

2. Хромато-масс-спектрометрическое пептидное картирование

Образцы анализируемых серий препаратов алтеплазы денатурировали в буферном растворе, содержащем 6 М мочевину и 0,1\% SDS (pH 8,6), затем восстанавливали 5 мM ДТТ в течение 1 ч при $50^{\circ} \mathrm{C}$. Алкилирование проводили при помощи раствора 20 мМ йодуксусной кислоты при комнатной температуре в темноте в течение 1 ч. Восстановленный и алкилированный белок переводили ультрафильтрацией в буферный раствор (50 мМ бикарбонат аммония, $\mathrm{pH} 8,2$ ) при помощи мембранного микроконцентратора с пределом проницаемости 3 кДа. Дегликозилирование образцов проводили обработкой пептид-N-гликозидазой F (ПНГаза F) при $37^{\circ} \mathrm{C}$ в течение 16 ч. Протеолиз проводили при температуре $40{ }^{\circ} \mathrm{C}$ в течение 6 ч при соотношении трипсина к алтеплазе $1 / 40$ (w/w). Реакцию останавливали титрованием трифрторуксусной кислотой до $\mathrm{pH} 2,0$.

Разделение триптических гидролизатов осуществляли на колонке Waters Acquity UPLC CSH Peptide, 2,1×100 мм, 1,7 мкм, $130 \AA$ (Waters). Применяли элюенты следующего состава: фраза A $-0,1 \%$ муравьиная кислота в воде, сраза B $-0,1 \%$ муравьиная кислота в ацетонитриле. Разделение проводили в градиентном режиме (2-26 \% В за 32 мин, 26-35\% В за 2 мин) при скорости потока 0,5 мл/мин.

\section{3. Молекулярная масса}

Определение проводили методом обращенно-фразовой ВЭЖХ-МС после очистки белков от полимеров и низкомолекулярных примесей при помощи ультрасрильтрации и дегликозилирования образца ПНГазой F. Разделение осуществляли на колонке Agilent PLRP-S, 2,1×50 мм, $1000 \AA$, 5,0 мкм. Применяли элюенты следующего состава: фраза $A-0,1 \%$ муравьиная кислота в воде, фаза $\mathrm{B}-0,1 \%$ муравьиная кислота в ацетонитриле. Разделение проводили в градиентном режиме (20-50 \% В за 11 мин) при скорости потока 0,25 мл/мин.

4. Профииль $N$-гликозилирования

Подготовку образцов проводили при помощи набора GlykoPrep N-Glycan Sample Preparation kit (ProZyme, \#GP96NGLB). Селективное дегликозилирование модифицированных остатков аспарагина осуществляли при помощи ПНГазы $\mathrm{F}$, затем проводили карбоксилирование образующихся гликозиламинов с образованием фолуоресцентных производных $\mathrm{N}$-гликанов. Разделение меченых олигосахаридов проводили при помощи гидрофильной ВЭЖХ с использованием колонки TSKgel Amide-80, 2,0×150 мм, 3 мкм (Tosoh Bioscience) при скорости потока 0,2 мл/мин. Использовали элюенты следующего состава: фраза А - 60 мМ формиат аммония в воде с добавлением $75 \%$ ацетонитрила, фраза В - водный 115 мМ раствор формиата аммония с $54 \%$ ацетонитрила. Для лучшего разделения применяли градиент от 20 до $70 \%$ В в течение 100 мин. Детекцию N-гликанов осуществляли по сигналу фолуоресценции при 345 нм в результате возбуждения светом с длиной волны 285 нм.

5. Масс-спектрометрические измерения

Во всех экспериментах для определения $m / z$ (отношения массы к заряду) использовали времяпролетный квадруполь-

${ }^{3}$ European Pharmacopoeia 9th Edition. 07/2013:1677 Alteplase for injection. 
ный масс-детектор Agilent QTOF 6550 с источником ионов Dual Jet Stream в режиме мониторинга положительных ионов. При измерении массы полноразмерного белка деконволюцию спектров выполняли методом максимальной энтропии. Для подтверждения аминокислотной последовательности детектирование проводили, используя фронтально-зависимый тандемный режим сканирования. При соотнесении регистрируемых масс пептидов с их возможной структурой учитывались наиболее распространенные посттрансляционные модификации: дезамидирование глутамина и аспарагина, окисление, а также 0-гликозилирование. Массу анализируемых N-гликанов вычисляли в виде разницы: $M-261,14773$, где $M$ - регистрируемое значение массы олигосахаридов, меченных фрлуорофоpom InstantPC ${ }^{\mathrm{TM}}$.

\section{6. Сиаловые кислоты}

Определение общего содержания сиаловых кислот проводили резорциноловым методом Свеннерхольма. Для этого к 100 мкл образцов алтеплазы (2 мг/мл) прибавляли 20 мкл 40 мМ йодной кислоты и инкубировали в течение 35 мин на льду, затем прибавляли 250 мкл резорцинолового реагента и после инкубации в течение 5 мин на льду переносили образцы в термостат, нагретый до $95^{\circ} \mathrm{C}$. Через 15 мин образцы охлаждали до комнатной температуры, прибавляли по 250 мкл этанола и инкубировали 3 мин при $37^{\circ} \mathrm{C}$. После охлаждения до комнатной температуры измеряли поглощение при длине волны 600 нм.

\section{7. Нейтральные сахара}

Количественное определение нейтральных сахаров в образцах алтеплазы проводили согласно методике, описанной B EP $9.0^{4}$.

8. Электрофорез в полиакриламидном геле (ПААГ ЭФ)

Анализ образцов алтеплазы проводили по методу Лэммли в $10 \%$ полиакриламидном геле в восстанавливающих условиях, перед анализом образцы прогревали при $100{ }^{\circ} \mathrm{C}$ в течение 5 мин в присутствии ДТТ. Окрашивание солями серебра проводили согласно инструкции к набору Silver Stain Plus ${ }^{\mathrm{TM}}$ kit (Bio-Rad).

\section{9. Содержание мономера и одноцепочечной формы}

Для количественного определения хроматографической чистоты (содержание мономера), а также содержания одноцепочечной формы алтеплазы применяли гель-фильтрационную хроматографию на колонке TSK gel G3000SW 7,5×600 мM (Tosoh Bioscience, Германия) с использованием подвижной фазы на основе фоссратного буфрерного раствора, содержащего $0,1 \%$ SDS. В нативных условиях образцы анализировали без предварительной пробоподготовки; для определения содержания одноцепочечной и двухцепочечной срорм алтеплазы дисульфидные связи в образцах предварительно восстанавливали при помощи ДТТ.

10. Взаимодействие алтеплазы с фиибрином

Для количественной характеристики специфического взаимодействия алтеплазы с фибрином использовали метод поверхностного плазмонного резонанса на приборе Biacore T200 (GE, США). Для этого фрибриноген ковалентно иммобилизовали на поверхность сенсора СM5, после чего конвертировали в фибрин в присутствии тромбина, как описано P. Björquist [1]. Для определения равновесной константы диссоциации (KD) комплекса алтеплаза-фибрин использовали одноцикловый анализ, при котором последовательно без промежуточных регенераций на поверхность сенсора с иммобилизованным фрибрином подавали разные концентрации алтеплазы. По достижении равновесия между свободной и связанной формами алтеплазы при данной концентрации алтеплазы и при равном количестве иммобилизованного на сенсоре фрибрина вычисляли равновесную KD образования межмолекулярного комплекса.

\section{1. Взаимодействие алтеплазы с PAl-1}

Для количественной характеристики специфического взаимодействия алтеплазы с PAI-1 использовали метод поверхностного плазмонного резонанса на приборе Biacore T200 (GE, CША). PAl-1 (ингибитор активации плазминогена первого типа) относится к классу серпинов, для них характерно практически необратимое взаимодействие с мишенью [2]. В связи с этим для сравнительной характеристики вычисляли кинетические константы скорости ассоциации формирующегося комплекса. Для этого PAI-1 ковалентно иммобилизовали на поверхность сенсора CM5 до уровня $300 \mathrm{RU}$, после чего подавали возрастающие концентрации алтеплазы, наблюдая в реальном времени за скоростью формирования комплекса на поверхности сенсора. Анализ проводили в одноцикловом формате, после чего вычисляли кинетическую константу скорости ассоциации формирующегося на сенсоре комплекса.

\section{2. Определение активности алтеплазы}

Определение активности алтеплазы в составе референтного лекарственного препарата Актилизе ${ }^{\circledR}$ и активности алтеплазы в составе биоаналогичного препарата Ревелиза ${ }^{\circledR}$ проводили согласно методике, описанной в ЕР $9.0^{5}$. Для этого в пробирки вносили по 1 мл раствора фибриногена (2 мг/мл) и 20 мкл раствора плазминогена (1 мг/мл). В другой набор пробирок вносили 300 мкл раствора тромбина и по 300 мкл раствора стандартного образца или раствора испытуемых образцов, которые затем добавляли в пробирки, содержащие смесь плазминоген/ фибриноген. Время добавления раствора фиксировали. Перемешивали полученную смесь и переносили пробирки в водяную баню, предварительно прогретую до $37^{\circ} \mathrm{C}$. В течение приблизительно 30 с образовывался сгусток. Время лизиса сгустка определяли как время от момента добавления образца в раствор до момента поднятия на поверхность последнего пузырька воздуха.

С помощью калибровочного графика зависимости десятичного логарифма активности стандарта $\lg (U)$ от десятичного логарифрма значения времени лизиса $\lg (t)$ определяли специфическую фибринолитическую активность алтеплазы.

\section{Результаты и обсуждение}

Рекомбинантный белок ТPA имеет три сайта N-гликозилирования. Известно, что первый (Asn117) модифицирован преимущественно олигоманнозными и, в меньшей мере, гибридными олигосахаридами [3], в то время как два остальных сайта (Asn184 и Asn448) содержат преимущественно комплексные структуры [4]. Помимо N-гликанов молекула алтеплазы также содержит связанную по остатку треонина (Thr61) фукозу [5]. Показано, что вариабельность модификации по сайту Asn184 приводит к образованию фрорм белка С двумя (тип II) или тремя (тип I) присутствующими олигосахаридными фрагментами. Как правило, рекомбинантный tPA синтезируется в виде смеси молекул обоих типов в соотношении, близком к единице [6]. Функциональные различия между формами выражаются в аффринности к фибрину (II тип связывает лучше), а также на уровне скорости выведения препарата из организма [7-9].

\footnotetext{
${ }^{4}$ European Pharmacopoeia 9th Edition. 07/2013:1677 Alteplase for injection.

${ }^{5}$ Там же.
} 


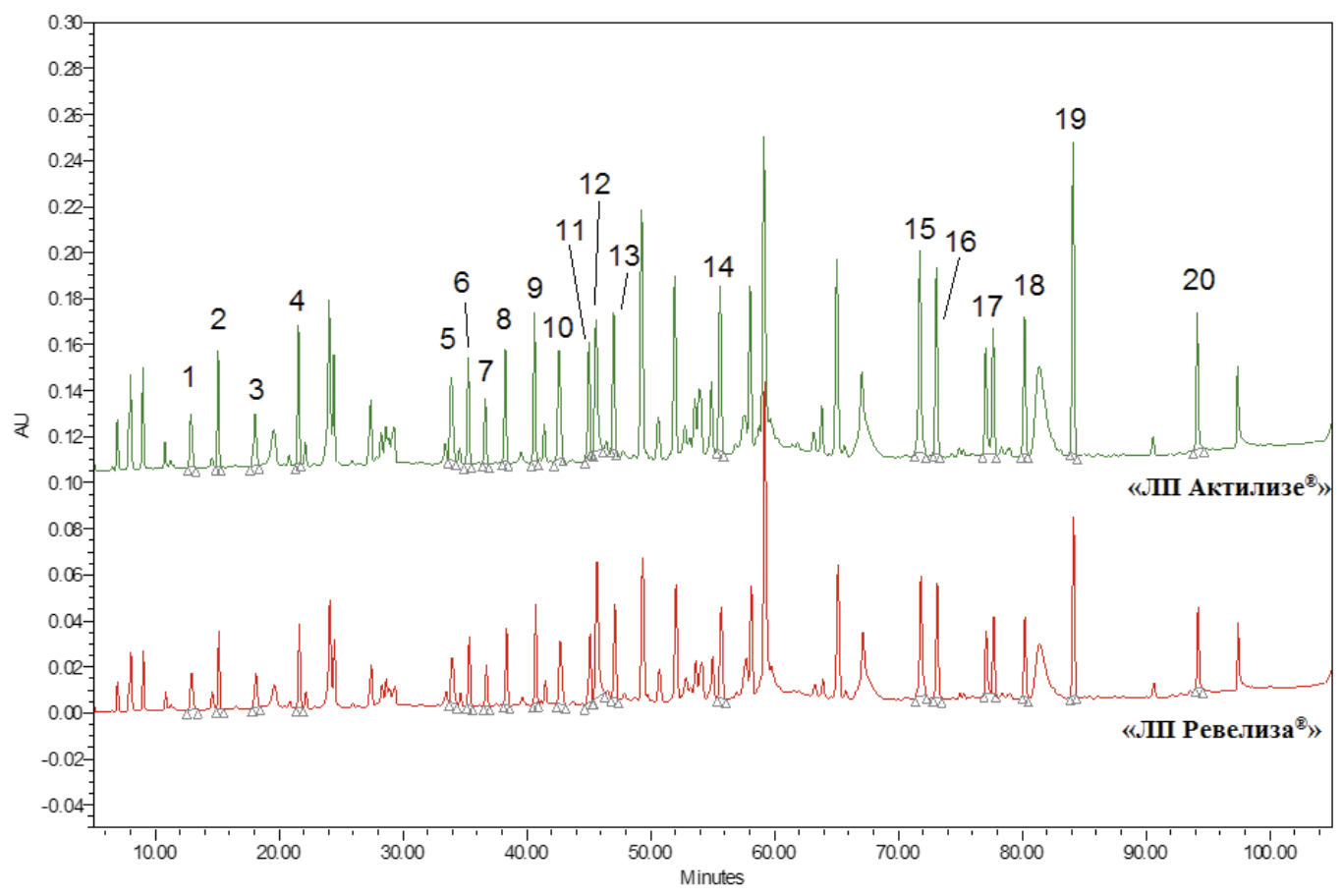

Рис. 2. Пептидное картирование алтеплазы (аминокислотная последовательность пептидов указана в таблице 1). Fig 2. Peptide mapping of alteplase (the amino acid sequence of peptides is shown in Table 1).

\section{Первичная структура}

Для подтверждения идентичности первичной структуры алтеплазы в сравниваемых препаратах было проведено пептидное картирование триптических гидролизатов методом ОФВЭЖХ. При сравнении пептидныХ карт рефрерентного и биоаналогичного препаратов (рис. 2) различий выявлено не было, полученные хроматограммы совпадают с пептидной картой алтеплазы, приведенной в ЕР 9.06. Идентисрицированные таким способом пептидные фррагменты (табл. 1) представляют более 55 \% всей последовательности молекулы [10].

Интактные молекулярные массы одноцепочечной и двухцепочечной форм алтеплазы, определенные массспектрометрически, составили 56958 и 34776 Да соответственно при полном совпадении спектров сравниваемых препаратов (рис. 3). Помимо определения молекулярной массы используемая методика позволила провести полное подтверждение аминокислотной последовательности молекулы алтеплазы в составе всех сравниваемых образцов. Также была проведена идентификация сайтов посттрансляционных модификаций, в результате которой было подтверждено наличие 11 сайтов дезамидирования $\left(\mathrm{Q}_{17}, \mathrm{~N}_{29}, \mathrm{Q}_{42}, \mathrm{~N}_{140}, \mathrm{~N}_{205}, \mathrm{Q}_{222}, \mathrm{Q}_{75}, \mathrm{~N}_{95}, \mathrm{~N}_{211}, \mathrm{~N}_{241}\right.$, $\left.\mathrm{N}_{249}\right)$ и трех сайтов окисления $\left(\mathrm{M}_{13}, \mathrm{M}_{180}, \mathrm{M}_{207}\right)$. Также в каждом из белков были подтверждены два сайта N- и один сайт 0-гликозилирования.

На основании совокупности полученных данных по анализу первичной структуры алтеплазы ресрерентного препарата и препарата-аналога можно сделать вывод об идентичности их аминокислотной последовательности и сходстве характера посттрансляционных модификаций.

\section{Гликозилирование}

В ходе данного исследования было проведено количественное определение индивидуальных компонентов просриля
$\mathrm{N}$-гликанов методом ВЭЖХ гидрофильного взаимодействия с одновременным подтверждением их структуры при помощи сканирующего масс-спектрометра. Для этого проводили высокоспецифическое ферментативное отщепление гликанов от молекулы белка с последующей модификацией фрлуорофором InstantPC ${ }^{\mathrm{TM}}$. Основной набор наблюдаемых структур представлен на рисунке 4 и является в значительной мере сходным среди сравниваемых препаратов. Уникальные гликаны обнаружены не были. Хотя Актилизе ${ }^{\circledR}$ и Ревелиза ${ }^{\circledR}$ продемонстрировали небольшие различия в процентном распределении олигосахаридов и их групп, тем не менее везде основной вклад вносили олигоманнозные структуры, а также би-, три- и полиантенные комплексные гликаны, что согласуется с данными литературы $[3,4,6]$. В исследуемых образцах в незначительном количестве были обнаружены остатки N-гликолилнейраминовой кислоты, которые могут входить в гликановый состав белков, синтезируемых клетками СНО. Другой из известных антигенов углеводной природы - мотив Gal( $\alpha 1,3)$-Gal - зарегистрирован не был. Поскольку часто функциональное влияние оказывается не отдельной модификацией, а целой группой сходных по структуре олигосахаридов, проведение оценки вкладов индивидуальных компонентов гликопросриля принято осуществлять на комплексном уровне. Ряд таких интегральных характеристик представлен в таблице 2.

Сходство/подобие профилей гликозилирования ресрерентного и исследуемого препаратов является основанием для заключения на этапе оценки качества вопроса о рассмотрении разработанного препарата как биоподобного. В ходе исследования были установлены отличия в процентном содержании мультиантенных комплексных гликанов. Нужно отметить, что все структуры этой группы содержат до четырех остатков $\mathrm{N}$-ацетилнейраминовой кислоты одновременно и являются наиболее весомыми носителями отрицательного заряда. Таким

${ }^{6}$ European Pharmacopoeia 9th Edition. 07/2013:1677 Alteplase for injection. 
В. Д. Гусарова, М. С. Пантюшенко, В. М. Симонов, Р. Р. Шукуров, Р. А. Хамитов, А. Ю. Вишневский V. D. Gusarova, M. S. Pantyushenko, V. M. Simonov, R. R. Shukurov, R. A. Khamitov, A. Yu. Vishnevskiy

Таблица 1. Список идентифицированных пептидных фрагментов алтеплазы (пептидное картирование ОФ-ВЭЖХ)

Table 1. The list of identified peptide fragments of alteplase (peptide mapping by RP-HPLC)

\begin{tabular}{|c|c|c|c|}
\hline Пик & Триптический пептид & Фрагмент & Последовательность \\
\hline 1 & T7 & $50-55$ & SCSEPR \\
\hline 2 & T20 & 229-233 & HNYCR \\
\hline 3 & $\mathrm{~T} 12$ & $130-135$ & RPDAIR \\
\hline 4 & T36 & $357-361$ & YIVHK \\
\hline \multirow{4}{*}{5} & ТЗа & $11-23$ & TQMIYQQHQSLR \\
\hline & T3c & $22-27$ & LRPVLR \\
\hline & T18a & 208-212 & ILIGK \\
\hline & T49 & $506-513$ & DVPGVYTK \\
\hline 6 & T25 & $268-275$ & QYSQPQFR \\
\hline 7 & T1 & $1-7$ & SYQVICR \\
\hline 8 & $\mathrm{~T} 10$ & $90-101$ & ATCYEDQGISYR \\
\hline 9 & $\mathrm{~T} 13$ & $136-145$ & LGLGNHNYCR \\
\hline \multirow{2}{*}{10} & T34 & $343-351$ & VVPGEEEQK \\
\hline & T35 & $352-356$ & FEVEK \\
\hline 11 & $\mathrm{~T} 46$ & $450-462$ & TVTDNMLCAGDTR \\
\hline \multirow{2}{*}{12} & T4 & $28-30$ & SNR \\
\hline & T5 & $31-40$ & VEYCWCNSGR \\
\hline \multirow{2}{*}{13} & $\mathrm{~T} 41$ & $417-427$ & HEALSPFYSER \\
\hline & T19 & $213-228$ & VYTAQNPSAQALGLGK \\
\hline \multirow{2}{*}{14} & T32a & $328-339$ & FPPHHLTVILGR \\
\hline & $\mathrm{T} 47$ & $463-489$ & SGGPQANLHDACQGDSGGPLVCLNDGR \\
\hline 15 & T50 & $514-522$ & VTNYLDWIR \\
\hline 16 & T37 & $362-378$ & EFDDDTYDNDIALLQLK \\
\hline 17 & T8 & $56-82$ & CFNGGTCQQALYFSDFVCQCPEGFAGK \\
\hline 18 & $\mathrm{~T} 18$ & $190-212$ & GTHSLTESGASCLPWNSMILIGK \\
\hline 19 & T27 & 278-291 & GGLFADIASHPWQAAIFAK \\
\hline 20 & $\mathrm{~T} 48$ & $490-505$ & MTLVGIISWGLGCGQK \\
\hline
\end{tabular}

Таблица 2. Процентная площадь пиков гликанов по данным ВЭЖХ гидрофильного взаимодействия Table 2. Percentage peak area of glycans determined by hydrophilic interaction HPLC

\begin{tabular}{|c|c|c|c|c|c|c|}
\hline \multirow{2}{*}{ Группа N-гликанов } & \multicolumn{3}{|c|}{ ЛП Актилизе ${ }^{\circledR}$} & \multicolumn{3}{|c|}{ лП Ревелиза ${ }^{\circledR}$} \\
\hline & 606428 & 604030 & 606119 & 011115 & 010116 & 020516 \\
\hline 1. Заряженные & 62,2 & 66,4 & 64,2 & 61,9 & 62,9 & 64,3 \\
\hline Среднее значение & \multicolumn{3}{|c|}{$64 \pm 2$} & \multicolumn{3}{|c|}{$63 \pm 1$} \\
\hline 2. Олигоманнозные & 31,1 & 28,6 & 29,7 & 28,6 & 32,1 & 29,9 \\
\hline Среднее значение & \multicolumn{3}{|c|}{$30 \pm 1$} & \multicolumn{3}{|c|}{$30 \pm 2$} \\
\hline 3. Фукозилированные & 65,1 & 58,9 & 63,1 & 58,4 & 63,9 & 60,2 \\
\hline Среднее значение & \multicolumn{3}{|c|}{$62 \pm 3$} & \multicolumn{3}{|c|}{$61 \pm 3$} \\
\hline 4. Галактозилированные & 69,3 & 66,6 & 64,9 & 68,5 & 67,8 & 70,9 \\
\hline Среднее значение & \multicolumn{3}{|c|}{$67 \pm 2$} & \multicolumn{3}{|c|}{$69 \pm 2$} \\
\hline 5. Комплексные биантенные & 42,6 & 37,2 & 34,8 & 32,2 & 28,3 & 33,6 \\
\hline Среднее значение & \multicolumn{3}{|c|}{$38 \pm 4$} & \multicolumn{3}{|c|}{$31 \pm 3$} \\
\hline 6. Комплексные мультиантенные & 26,4 & 30,1 & 27,4 & 40,1 & 34,8 & 39,1 \\
\hline Среднее значение & \multicolumn{3}{|c|}{$28 \pm 2$} & \multicolumn{3}{|c|}{$38 \pm 3$} \\
\hline 7. C N-гликолилнейраминовой кислотой & Не более 2 & Не более 4 & Не более 2 & Не более 1 & Не более 2 & Не более 1 \\
\hline Среднее значение & \multicolumn{3}{|c|}{ Не более 4} & \multicolumn{3}{|c|}{ Не более 2} \\
\hline
\end{tabular}


Одноцепочечная форма
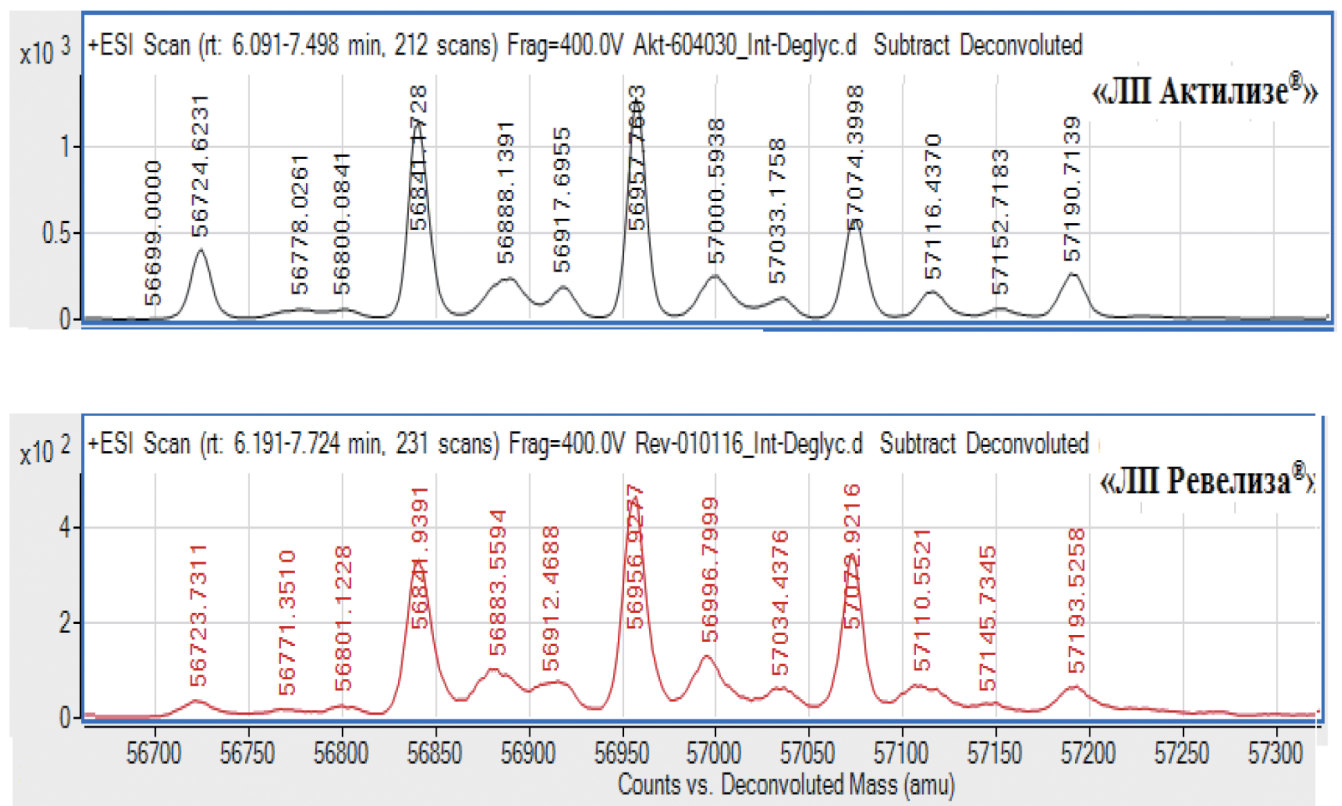

Двухцепочечная форма

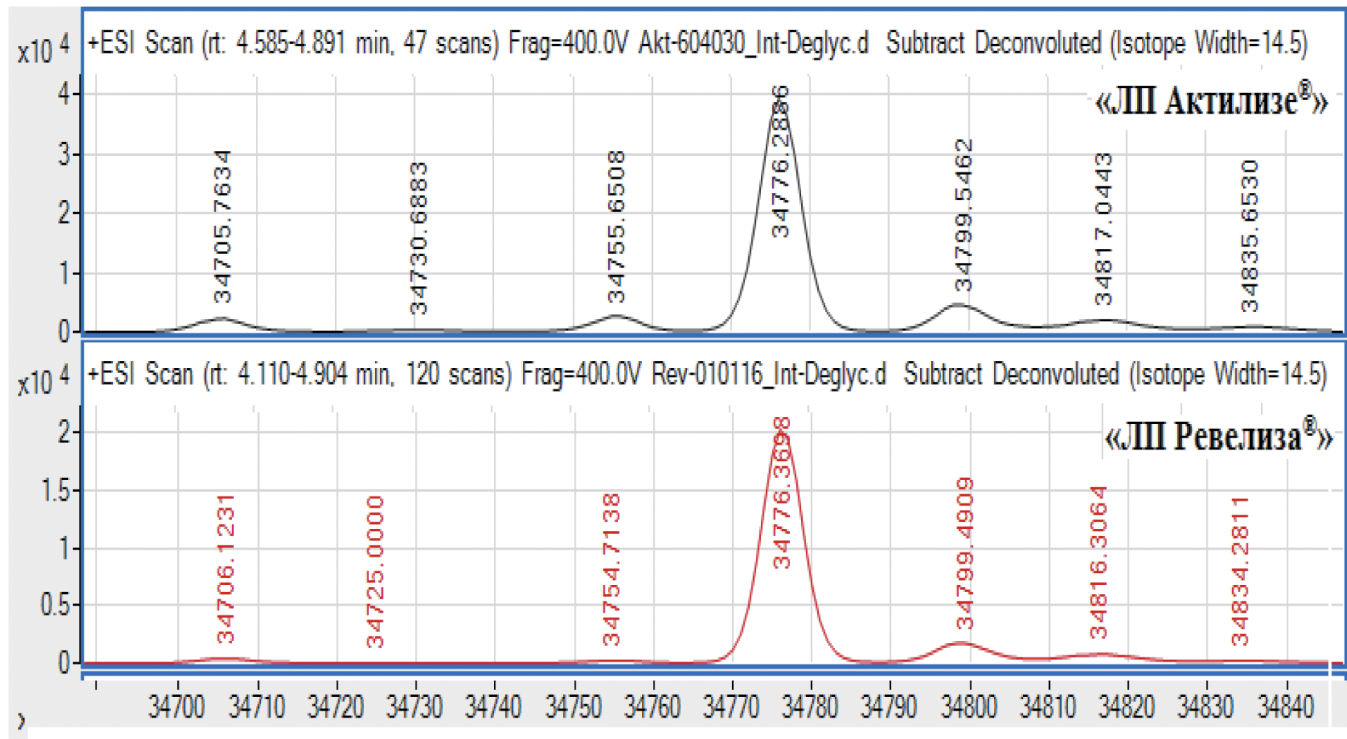

Рис. 3. Определение молекулярной массы алтеплазы.

Fig. 3. Determination of alteplase molecular weight.

образом, несмотря на сходные значения общих сумм площадей всех заряженных N-гликанов, для ЛП Ревелиза ${ }^{\circledR}$ стоило ожидать несколько большего абсолютного содержания сиаловой кислоты. Это предположение подтверждается результатом прямого определения сиаловых кислот (табл. 3), однако полученные значения не выходят за пределы рекомендуемых ЕР 9.0 норм.

Вместе с оценкой общего содержания нейтральных сахаров полученные данные позволяют считать исследованные препараты сопоставимыми, так как различия в количестве комплексных мультиантенных гликанов между препаратами могут быть отнесены к незначительным и не сказываются на биологических свойствах алтеплазы in vitro (табл. 4-6).

\section{Чистота}

Помимо вариаций паттерна гликозилирования нормируемым показателем качества ЛП алтеплазы является соотношение одноцепочечной (интактной) и двухцепочечной (рас- щепленной) фрорм молекулы. Интактная форма алтеплазы (1-527 аминокислотные остатки) при переходе в активную форму расщепляется между остатками $\mathrm{R}_{275}$ и $\mathrm{I}_{276}$, что приводит к образованию двух отдельных цепей 1-275 и 276-527, которые удерживаются вместе посредством дисульфидных связей (рис. 1). Среди продуктов расщепления пептид 276-527 обладает меньшей молекулярной массой и содержит единственный сайт $\mathrm{N}$-гликозилирования $\left(\mathrm{N}_{448}\right)$, в то время как второй из пептидов (1-275) обычно полностью гликозилирован по положению $\mathrm{N}_{117}$ и частично по положению $\mathrm{N}_{184}$. В том случае если последний из сайтов модифицирован (тип I), алтеплаза проявляет пониженную специфическую активность и сродство к фрибрину [7, 8]. Кроме того, эта форма отличается от негликозилированной (тип II) по молекулярной массе. Это позволяет идентифицировать их методом ПААГ ЭФ (рис. 5). Две близкие по интенсивности полосы в области 37 кДа свидетельствуют 
В. Д. Гусарова, М. С. Пантюшенко, В. М. Симонов, Р. Р. Шукуров, Р. А. Хамитов, А. Ю. Вишневский V. D. Gusarova, M. S. Pantyushenko, V. M. Simonov, R. R. Shukurov, R. A. Khamitov, A. Yu. Vishnevskiy

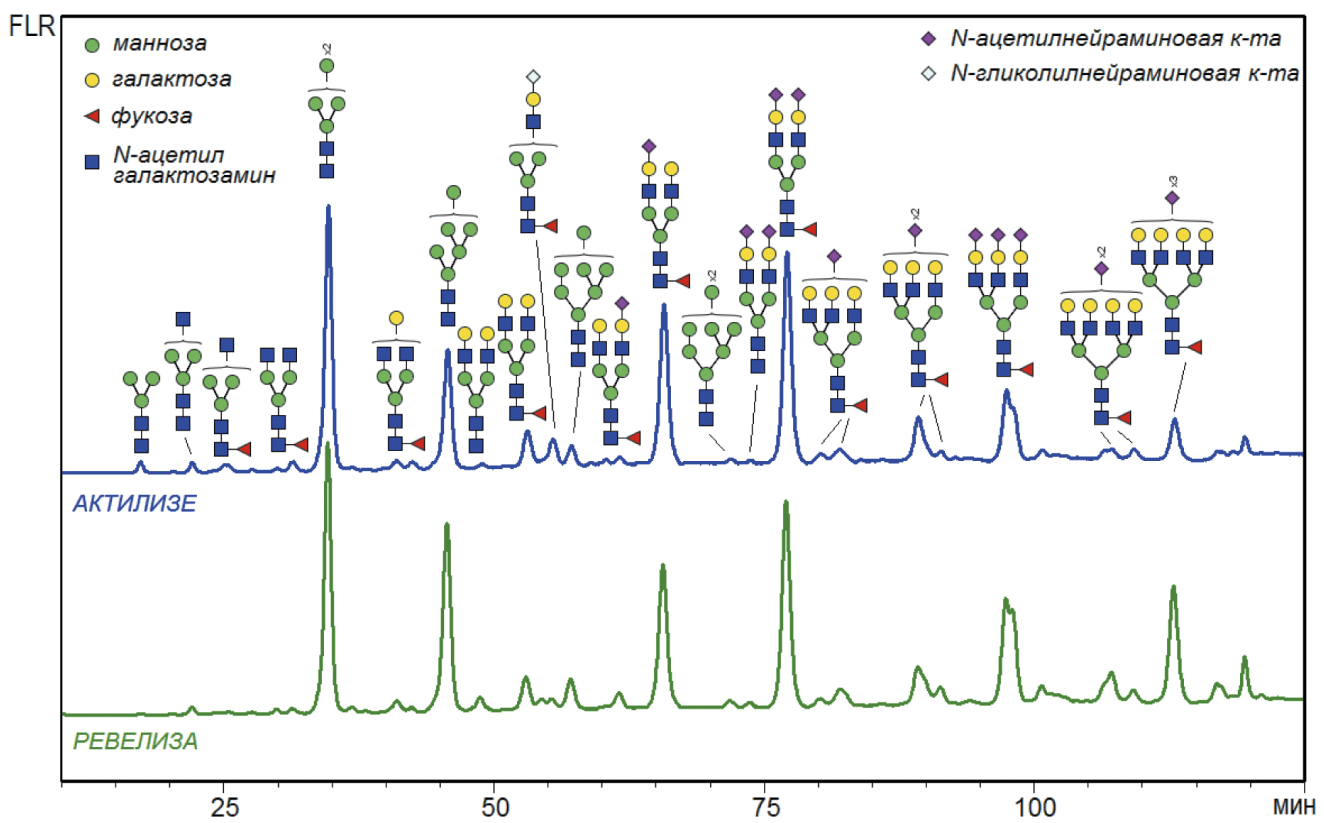

Рис. 4. Профиль N-гликозилирования алтеплазы.

Fig. 4. N-Glycosylation profile of alteplase.

Таблица 3. Содержание нейтральных сахаров и сиаловых кислот в ЛП Актилизе ${ }^{\circledR}$ и ЛП Ревелиза ${ }^{\circledR}$ Table 3. The content of neutral sugars and sialic acids in Actilyse ${ }^{\circledR}$ and Revelyse ${ }^{\circledR}$

\begin{tabular}{|c|c|c|c|c|c|c|c|}
\hline \multirow{3}{*}{ Модификация } & \multicolumn{7}{|c|}{ Содержание модификаций, моль, на моль алтеплазы } \\
\hline & \multicolumn{3}{|c|}{ ЛП Актилизе ${ }^{\circledR}$} & \multicolumn{3}{|c|}{ ЛП Ревелиза ${ }^{\circledR}$} & \multirow{2}{*}{ Норма по ЕР 9.0} \\
\hline & 606428 & 604030 & 606119 & 011115 & 010116 & 020516 & \\
\hline 1. Нейтральные сахара & 13,69 & 14,19 & 14,12 & 12,89 & 13,10 & 13,92 & \multirow{2}{*}{$8,4-15,6$} \\
\hline Среднее значение & \multicolumn{3}{|c|}{$14,00 \pm 0,27$} & \multicolumn{3}{|c|}{$13,30 \pm 0,54$} & \\
\hline 2. Сиаловые кислоты & 2,85 & 2,84 & 2,72 & 3,02 & 3,15 & 2,96 & \multirow{2}{*}{$2,1-3,9$} \\
\hline Среднее значение & \multicolumn{3}{|c|}{$2,80 \pm 0,07$} & \multicolumn{3}{|c|}{$3,04 \pm 0,10$} & \\
\hline
\end{tabular}

Таблица 4. Сравнение вычисленных равновесных констант диссоциации комплекса алтеплаза-фрибрин Table 4. Comparison of the calculated equilibrium dissociation constants of the alteplase-fibrin complex

\begin{tabular}{|c|c|c|c|c|}
\hline \multirow{2}{*}{ Алтеплаза } & \multirow{2}{*}{ Серия } & \multicolumn{2}{|c|}{$\mathrm{KD}, \mathrm{M}$} & \multirow{2}{*}{ Критерий сопоставимости, \% } \\
\hline & & измеренное & среднее по сериям & \\
\hline \multirow{3}{*}{ ЛП Актилизе ${ }^{\circledast}$} & 606428 & $4,59 \cdot 10^{-7}$ & \multirow{3}{*}{$(4,35 \pm 0,22) \cdot 10^{-7}$} & \multirow{3}{*}{100,0} \\
\hline & 604030 & $4,32 \cdot 10^{-7}$ & & \\
\hline & 606119 & $4,15 \cdot 10^{-7}$ & & \\
\hline \multirow{3}{*}{ ЛП Ревелиза ${ }^{\circledR}$} & 011115 & $4,42 \cdot 10^{-7}$ & \multirow{3}{*}{$(4,20 \pm 0,2) \cdot 10^{-7}$} & \multirow{3}{*}{103,5} \\
\hline & 010116 & $4,14 \cdot 10^{-7}$ & & \\
\hline & 020516 & $4,03 \cdot 10^{-7}$ & & \\
\hline
\end{tabular}

Таблица 5. Сравнение вычисленных кинетических констант скоростей ассоциации комплекса алтеплаза-PAl-1 Table 5. Comparison of the calculated kinetic rate constants of association of the alteplase-PAl-1 complex

\begin{tabular}{|c|c|c|c|c|}
\hline \multirow{2}{*}{ Алтеплаза } & \multirow{2}{*}{ Серия } & \multicolumn{2}{|c|}{$\mathrm{Ka}(1 / \mathrm{Ms})$} & \multirow{2}{*}{ Критерий сопоставимости, \% } \\
\hline & & измеренное & среднее по сериям & \\
\hline \multirow{3}{*}{ ЛП Актилизе ${ }^{\circledR}$} & 606428 & $2,13 \cdot 10^{6}$ & \multirow{3}{*}{$(2,20 \pm 0,09) \cdot 10^{6}$} & \multirow{3}{*}{100,0} \\
\hline & 604030 & $2,27 \cdot 10^{6}$ & & \\
\hline & 606119 & $2,20 \cdot 10^{6}$ & & \\
\hline \multirow{3}{*}{ ЛП Ревелиза ${ }^{\circledR}$} & 011115 & $2,10 \cdot 10^{6}$ & \multirow{3}{*}{$(2,12 \pm 0,02) \cdot 10^{6}$} & \multirow{3}{*}{103,8} \\
\hline & 010116 & $2,14 \cdot 10^{6}$ & & \\
\hline & 020516 & $2,12 \cdot 10^{6}$ & & \\
\hline
\end{tabular}


Таблица 6. Специфическая активность алтеплазы. Лизис фибринового сгустка

Table 6. Alteplase specific activity. Fibrin clot lysis

\begin{tabular}{|c|c|c|c|c|}
\hline \multirow{2}{*}{ Алтеплаза } & \multirow{2}{*}{ Серия } & \multicolumn{2}{|c|}{ Активность, МЕ/мг } & \multirow{2}{*}{$\begin{array}{c}\text { Критерий сопоставимо- } \\
\text { сти, \% }\end{array}$} \\
\hline & & измеренное & среднее по сериям & \\
\hline \multirow{3}{*}{ ЛП Актилизе } & 606428 & 624166,8 & \multirow{3}{*}{$625162 \pm 9589$} & \multirow{3}{*}{$106-109$} \\
\hline & 604030 & 616108,4 & & \\
\hline & 606119 & 635209,5 & & \\
\hline \multirow{3}{*}{ лП Ревелиза ${ }^{\circledR}$} & 011115 & 615216,2 & \multirow{3}{*}{$610424 \pm 17740$} & \multirow{3}{*}{$102-108$} \\
\hline & 010116 & 590779,9 & & \\
\hline & 020516 & 625276,0 & & \\
\hline
\end{tabular}

Таблица 7. Хроматографическая чистота и содержание одноцепочечной формы в препаратах алтеплазы Table 7. Chromatographic purity and the content of single-stranded form in alteplase products

\begin{tabular}{c|c|c|c}
\hline \multirow{2}{*}{ Форма алтеплазы } & \multicolumn{3}{|c}{ Содержание формы, \% } \\
\cline { 2 - 4 } & ЛП Актилизе ${ }^{\circledR}$ & ЛП Ревелиза & Норма по ЕР 9.0 \\
\hline Мономер & $97,90 \pm 0,17$ & $96,80 \pm 0,36$ & Не менее 95 \\
\hline Одноцепочечная фрорма & $82,2 \pm 0,4$ & $80,6 \pm 1,9$ & Hе менее 60 \\
\hline
\end{tabular}

о сопоставимом количестве молекул алтеплазы обоих типов. Также на электрофореграмме идентифиццирется одноцепочечная форма 1-527, представляющая собой широкую полосу с молекулярной массой около 60 кДа, которая не разделяется на ПААГ ЭФ в силу избыточного гликозилирования.

Количественное соотношение одноцепочечной и двухцепочечной фрорм алтеплазы в референтном и биоаналогичном препаратах было определено при помощи гель-срильтрации одновременно с определением хроматографической чистоты (рис. 6). Предварительное расщепление дисульфидных связей при помощи ДТТ приводит к диссоциации двухцепочечной формы на два отдельных фррагмента с молекулярными массами около 30 кДа, один из которых содержит крингл-домен, другой - протеазный домен. Как следует из полученных данных (табл. 7), сравниваемые препараты сопоставимы как по хроматографической чистоте (содержание мономера), так и по содержанию одноцепочечной формы.

\section{Сродство к фибрину и PAI-1}

Специфическое сродство алтеплазы к фиибину и PAl-1 проявляется в процессе регуляции фрибринолиза путем активации плазминогена в присутствии фиибинового сгустка. При этом природный ингибитор алтеплазы PAl-1 осуществляет контроль за количеством алтеплазы, способным активировать плазминоген. Для сравнительной характеристики специфического сродства ЛП Актилизе ${ }^{\circledR}$ и ЛП Ревелиза ${ }^{\circledR}$ в реальном времени сравнивали скорости формирования межмолекулярных комплексов алтеплазы как с фибрином, так и с PAl-1. Данные результатов анализа трех серий каждого препарата представлены в таблицах 4 и 5. Полученные данные позволяют считать ЛП биоподобными при критерии сопоставимости (отношение значений серии ресрерентного препарата к остальным измеренным данным, выраженным в процентах), не выходящем за диапазон 80-125\%.

\section{Определение активности алтеплазы}

Тканевой активатор плазминогена (tPA, алтеплаза) один из ключевых компонентов системы лизиса фрибринового сгустка (фибринолиза). После системного введения препарата tPA находится в плазме в неактивной форме до связывания с фрибрином (нерастворимый белок, образующийся в процессе свертывания крови). tРА активирует переход плазминогена

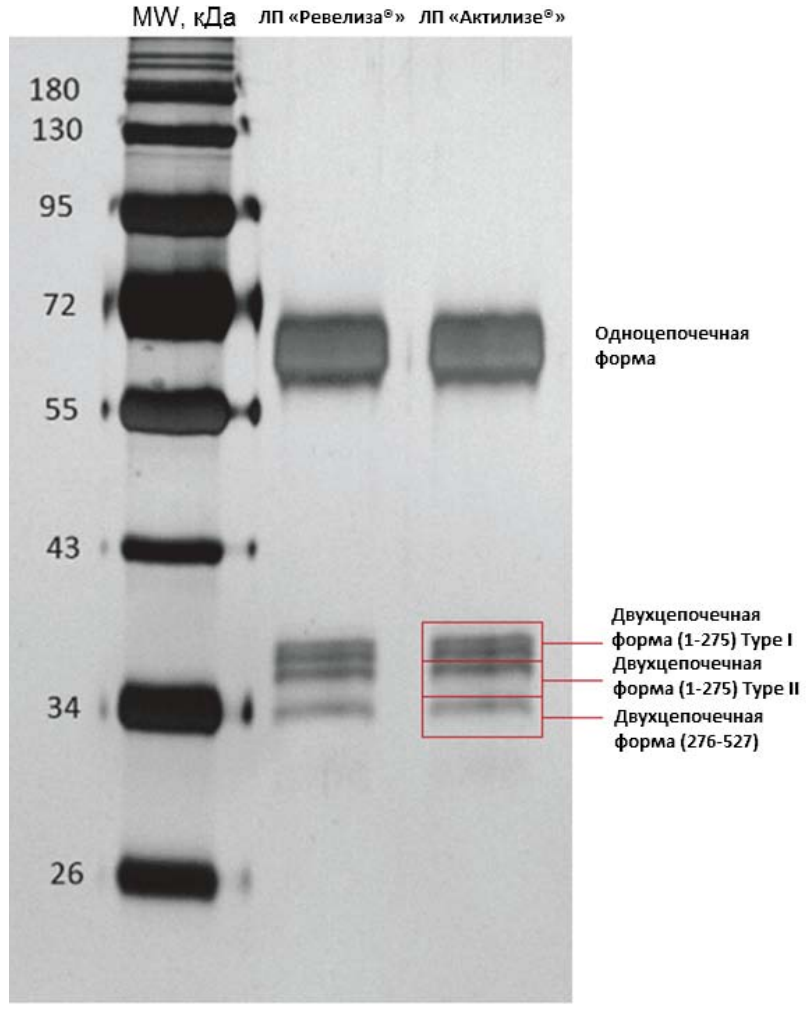

Рис. 5. Электрофореграмма алтеплазы в полиакриламидном геле в денатурирующих условиях.

Fig. 5. Electrophoregram of alteplase in polyacrylamide gel under denaturing conditions.

в плазмин, который, в свою очередь, осуществляет деградацию фибрина, что ведет к растворению фибринового сгустка и повышает тромболизис (растворение сгустка крови) только в ткани тромба.

Как следует из данных, представленных в таблице 6, специсфическая активность ЛП Ревелиза ${ }^{\circledR}$ сопоставима с активностью референтного препарата Актилизе ${ }^{\circledR}$. Данные значения входят в рекомендуемый ЕР 9.0 диапазон 90-110\% от установленной эталонной активности 580000 ME/мг. 


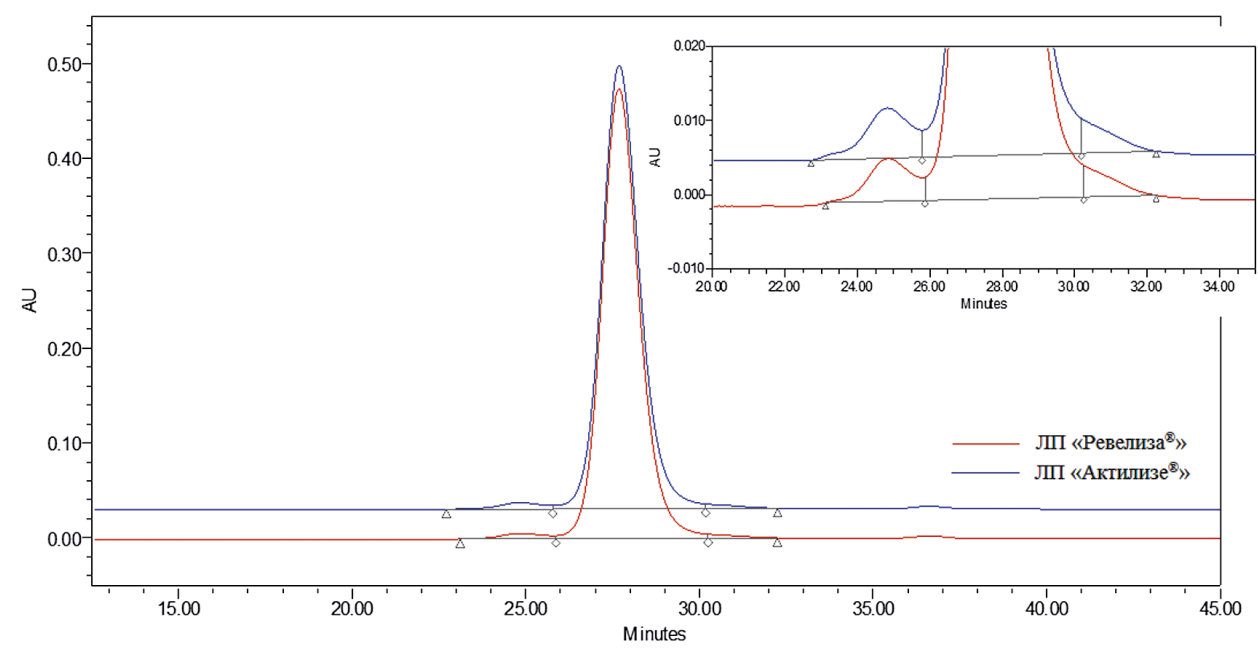

b

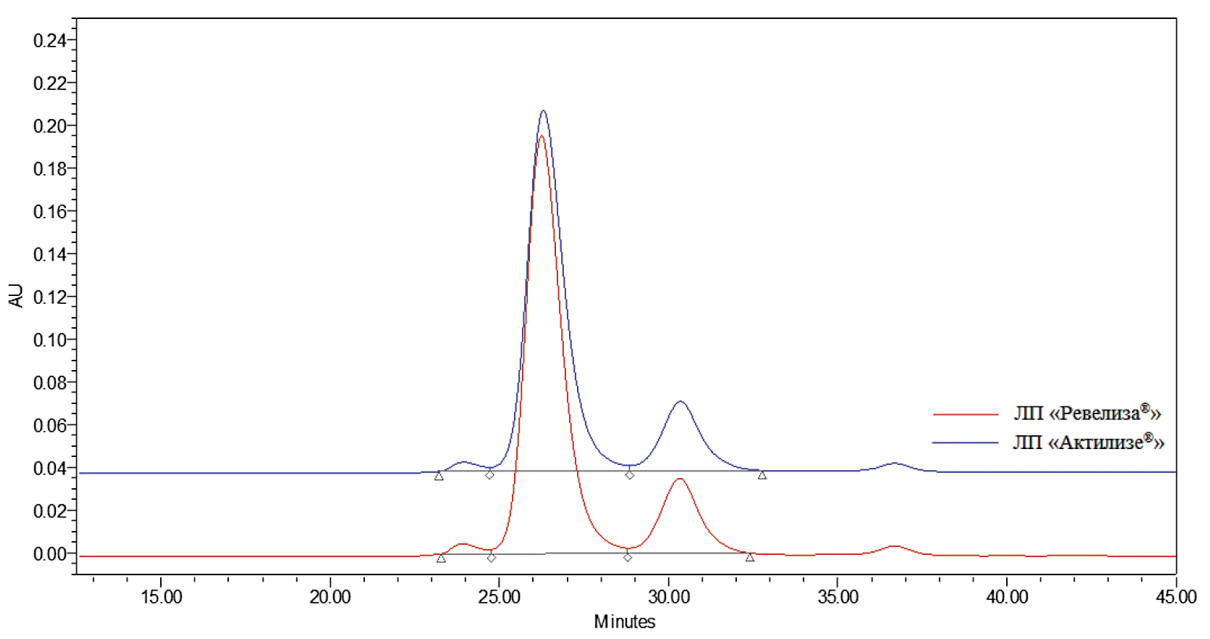

Рис. 6. Содержание мономера (a) и одноцепочечной фрормы (b), определенное методом гель-фильтрации. Fig. 6. The content of monomer (a) and single-chain form (b) determined by gel filtration.

\section{Заключение}

В ходе данного исследования была проведена комплексная сравнительная характеристика алтеплазы в составе референтного лекарственного препарата Актилизе ${ }^{\circledR}$ и биоаналогичного препарата Ревелиза ${ }^{\circledR}$. В случае сложных белковых молекул, таких как алтеплаза, необходимо подтвердить как идентичность первичной аминокислотной последовательности, так и детально характеризовать участки молекулы, влияющие на биологическую активность и потенциальную безопасность.

Одним из фракторов, влияющих на активность алтеплазы (лизис сгустка), является профиль гликозилирования, который незначительно различается у сравниваемых препаратов. Содержание индивидуальных гликанов, определенное при помощи ВЭЖХ гидросрильного взаимодействия, в случае ЛП Ревелиза ${ }^{\circledR}$ по отношению к референтному ЛП Актилизе ${ }^{\circledR}$ сдвинуто в сторону комплексных разветвленных структур, содержащих сиаловую кислоту, что подтверждается анализом общего ее количества, а также анализом содержания нейтральных сахаров.

Тем не менее препараты продемонстрировали высокую степень сходства/подобия при исследовании специфичности и активности алтеплазы, несмотря на различия в количестве комплексных мультиантенных гликанов между препаратами.

Известно, что при попадании в организм пациента вся одноцепочечная фрорма практически мгновенно переходит в активную двухцепочечную, в связи с чем ЕР 9.0 регламентирует содержание одноцепочечной формы в количестве не менее $60 \%$. Определение содержания соотношения одноцепочечной/двухцепочечной форм было проведено двумя независимыми методами: ПААГ ЭФ и гель-срильтрационной ВЭЖХ. Электрофоретические профили сравниваемых препаратов демонстрируют высокую степень сходства; количественное содержание одноцепочечной формы близко к 80 \%. Также при помощи выбранных методик была продемонстрирована сопоставимая степень чистоты препаратов.

Показано, что специсрическая активность сравниваемых препаратов, а также их сродство к фрибрину и PAI-1 (необходимое для регуляции фибринолиза) статистически сопоставимы.

На основании полученных данных, указывающих на отсутствие различий в структуре, выявленной незначительной гетерогенности в зарядах и содержании примесей, а также сопоставимой специфической активности, может быть сделано заключение о том, что лекарственный препарат Ревелиза ${ }^{\circledR}$ биоаналогичен ресрерентному препарату Актилизе ${ }^{\circledR}$ по фризико-химическим и биологическим свойствам.

Благодарности. Выражаем благодарность всему коллективу отдела аналитических методов МБЦ «ГЕНЕРИУМ» за советы и поддержку в работе над проектом. Научному сотруднику М.А. Смолову за разработку методов анализа 
гликанов и важные замечания к статье. Исследование проводилось без спонсорской поддержки.

Acknowledgments. The authors express their gratitude to the entire team of the Analytical Methods Department of the International Biotechnology Center "GENERIUM» for their advice and support with regard to this project; and to the researcher M.A. Smolov for the development of methods of glycan analysis and important comments on the paper. The study was performed without external funding.

Информация об отсутствии конфликта интересов. Авторы заявляют об отсутствии конфрликта интересов, требующего раскрытия в данной статье.

Conflict of interest. Authors declare no conflict of interest requiring disclosure in this article.

\section{Литература/References}

1. Guzzetta AW, Basa LJ, Hancock WS, Keyt BA, Bennett WF. Identification of carbohydrate structures in glycoprotein peptide maps by the use of LC/MS with selected ion extraction with special reference to tissue plasminogen activator and a glycosylation variant produced by site directed mutagenesis. Anal Chem. 1993;65(21):2953-62.

2. Spellman MW, Basa LJ, Leonard CK, ChakelJA, O'Connor JV, Wilson S, van Halbeek H. Carbohydrate structures of human tissue plasminogen activator expressed in Chinese hamster ovary cells. J Biol Chem. 1989;264(24):14100-11.

3. Harris RJ, Leonard CK, Guzzetta AW, Spellman MW. Tissue plasminogen activator has an O-linked fucose attached to threonine-61 in the epidermal growth factor domain Biochemistry. 1991;30(9):2311-4.

\section{Об авторах}

Гусарова Валентина Дмитриевна, канд. биол. наук, старший научный сотрудник отдела аналитических методов ООО «Международный биотехнологический центр «ГЕНЕРИУМ»

Пантюшенко Мария Семеновна, канд. биол. наук, старший научный сотрудник отдела аналитических методов ООО «Международный биотехнологический центр «ГЕНЕРИУМ»

Симонов Владимир Михайлович, научный сотрудник отдела аналитических методов ООО «Международный биотехнологический центр «ГЕНЕРИУМ», ORCID: https://orcid.org/0000-0002-0879-5595

Шукуров Рахим Рахманкулыевич, канд. биол. наук, начальник лаборатории физико-химических методов отдела аналитических методов ООО «Международный биотехнологический центр «ГЕНЕРИУМ»,

ORCID: https://orcid.org/0000-0002-6532-7835

Хамитов Равиль Авгатович, д-р мед. наук, профрессор, генеральный директор ООО «Международный биотехнологический центр «ГЕНЕРИУМ»,

ORCID: https://orcid.org/0000-0002-1314-894X

Вишневский Александр Юрьевич, канд. биол. наук, начальник отдела аналитических методов ООО «Международный биотехнологический центр «ГЕНЕРИУМ», ORCID: https://orcid.org/0000-0002-7865-9361

Поступила 07.02.2019

После доработки 13.02.2019

Принята к публикации 14.02.2019
4. Parekh RB, Dwek RA, Thomas JR, Opdenakker G, Rademacher TW, Wittwer AJ, et al. Cell-type-specific and site-specific N-glycosylation of type I and type II human tissue plasminogen activator. Biochemistry. 1989;28(19):7644-62.

5. Wittwer AJ, Howard SC, Carr LS, Harakas NK, Feder J, Parekh RB, et al. Effects of N-glycosylation on in vitro activity of Bowes melanoma and human colon fibroblast derived tissue plasminogen activator. Biochemistry. 1989;28(19):7662-9.

6. Berg DT, Burck PJ, Berg DH, Grinnell BW. Kringle glycosylation in a modified human tissue plasminogen activator improves functional properties. Blood. 1993;81(5):1312-22.

7. Cole ES, Nichols EH, Poisson L, Harnois ML, Livingston DJ. In vivo clearance of tissue plasminogen activator: The complex role of sites of glycosylation and level of sialylation. Fibrinilysis. 1993;7(1):15-22. https://doi.org/10.1016/02689499(93)90050-6

8. Chloupek RC, Harris RJ, Leonard CK, Keck RG, Keyt BA, Spellman MW, et al. Study of the primary structure of recombinant tissue plasminogen activator by reversedphase high-performance liquid chromatographic tryptic mapping. J Chromatogr. 1989;463(2):375-96.

9. Kim PY, Tieu LD, Stafford AR, Fredenburgh JC, Weitz JI. A high affinity interaction of plasminogen with fibrin is not essential for efficient activation by tissue-type plasminogen activator. J Biol Chem. 2012;287(7):4652-61. https://doi. org/10.1074/jbc.M111.317719

10. Björquist $P$, Brohlin $M$, Ehnebom J, Ericsson $M$, Kristansen $C$, Pohl G, Deinum J. Plasminogen activator inhibitor type-1 interacts exclusively with the proteinase domain of tissue plasminogen activator. Biochim Biophys Acta. 1994;1209(2):191-202.

\section{Authors}

Valentina D. Gusarova, Candidate of Biological Sciences, Senior Scientist of the Analytical Methods Department of the International Biotechnology Center «GENERIUM»

Maria S. Pantyushenko, Candidate of Biological Sciences, Senior Scientist of the Analytical Methods Department of the International Biotechnology Center «GENERIUM»

Vladimir M. Simonov, Scientist of the Analytical Methods Department of the International Biotechnology Center «GENERIUM», ORCID: https://orcid.org/0000-0002-0879-5595

Rakhim R. Shukurov, Candidate of Biological Sciences, Head of Laboratory of Physicochemical Methods, Analytical Methods Department of the International Biotechnology Center «GENERIUM», ORCID: https://orcid.org/0000-0002-6532-7835

Ravil A. Khamitov, Doctor of Medical Science, Professor, General Director of the International Biotechnology Center «GENERIUM», ORCID: http://orcid.org/0000-0002-1314-894X

Aleksandr Yu. Vishnevskiy, Candidate of Biological Sciences, Head of the Analytical Methods Department of the International Biotechnology Center "GENERIUM",

ORCID: https://orcid.org/0000-0002-7865-9361

Received 7 February 2019

Revised 13 February 2019

Accepted 14 February 2019 